
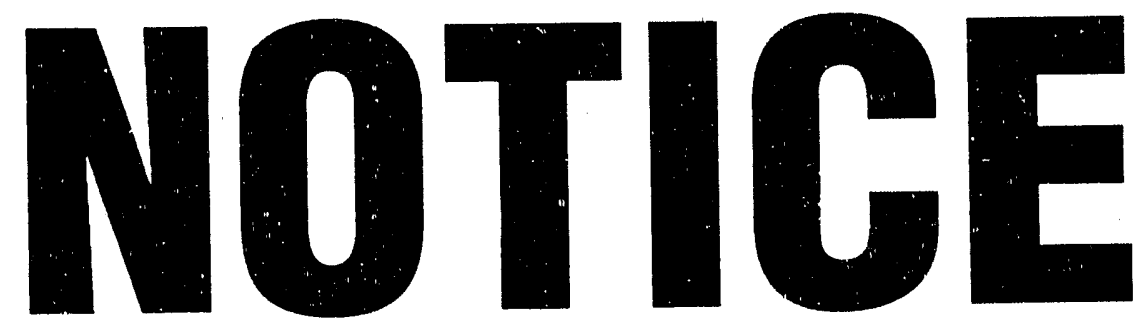

\title{
GERTAN DATA
}
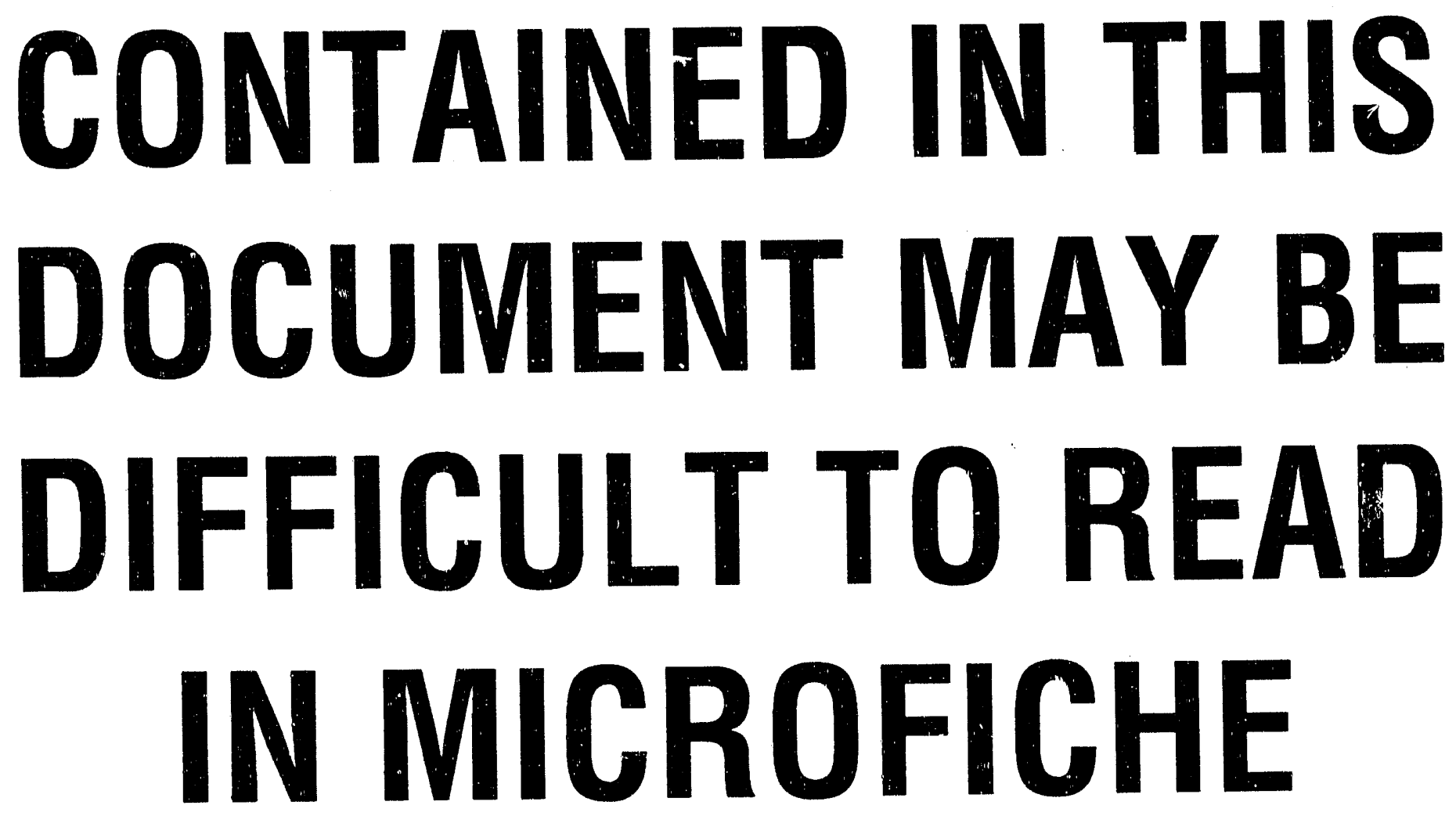

$$
\text { PRODUCTS. }
$$


$\mathrm{DOE} / \mathrm{AL} / 23711--2$

DUE-AL/23711-2

DE9 1006931

Acurex Technical Report TR-86-101/EED

INNOVATIVE POINT FOCUS

SOLAR CONCENTRATOR

Task 2(b) Topical Report: Optical Element Evaluation

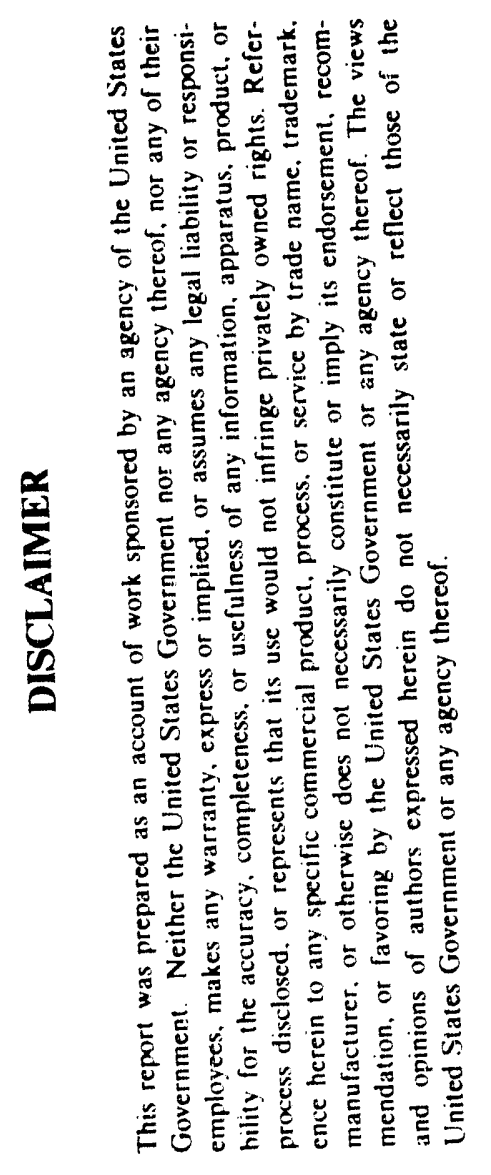

February 1986

\author{
For \\ U.S. Department of Energy \\ Albuquerque Operations Office \\ P.0. Box 5400 \\ Albuquerque, New Mexico 87115
}

By

Acurex Corporation

Energy \& Environmental Division

$485 \mathrm{Cl}$ yde Avenue

P.O. Box 7044

Mountain View, CA 94039 


\section{INTRODUCTION}

Acurex Corporation has a Cooperative Ayreement with the United States Department of Energy (DOE) to design, build and test a 15-meter diameter Innovative Point Focus Solar Concentrator. This report presents the results of the Phase 1 prototype reflective panel optical test.

The approach selected for this test was a quick, simple, and relatively inexpensive evaluation of the first outer reflective panel produced. This approach represented a tradeoff between extent of results and test costs. The test measured the focal quality of the panel, and this result was then related to the focal quality of the complete dish assembly.

Acurex set a standard deviation slope error goal of $2 \mathrm{mr}$ for product on reflective panels installed in the concentrator. The components and assembly steps important in achieving this goal are the stamped back panel, the front sheet with reflective surface, the lamination of these two components to form the reflective panel, and assembly of these reflective panels to form the concentrator dish. Both the back and front panels meet all requiremenis previously set. The first laminated reflective panel exhibited acceptable, but less-than-desired focal quality. Adjustment of the lamination technique (discussed below) should provide this desired focal quality. Assembly of the panels into the concentrator was verified as part of the test setup and meets all requirements previously set. The test results therefore demonstrate that the slope error goal for reflective panels installed in the concentrator can be achieved.

The optical tests carried out on the fipst prototype panel were of the reverse image and direct focus type. For the first test a target representing the receiver was set up in the focal plane of the panel and the panel observed from a distance of $1400 \mathrm{ft}$. The image of the target as reflected by the panel 
was observed and photographed for evaluation of panel focal quality. A second test was carr: 1 out focussing the panel onto a fiberboard panel, allowing the fiberboard to burn in the high flux region, and measuring the hole diameter. The procedures and results are discussed in greater detail in the following paragraphs.

2. PROTOTYPE PAINEL DESIGN AND ASSEMBLY

The prototype outer reflective panel consists of silvered polymer film ( $3 M^{\prime}$ 'S ECP 300) laminated to the front panel sheet which is, in turn, bonded to the stamped-hat-section back panel. In order to ensure long life for the prototype, the surface to which the silvered firm is laminated is prepared with an acrylic paint. The front panel is aluminized cold-rolled steel. The back panei is made from deep-draw-quality steel with galvaneal finish. The adhesive used to bond the front and back panels is Pliogrip 6000 series, a 2-part urethane produced by Ashland Chemical.

The outer panel is approximately $14 \mathrm{ft}$ long, $4 \mathrm{ft}$ wide at the wide end, and $2 \mathrm{ft}$ wide at the narrow end. The design and construction of the reflective panel are detailed in Reference 1.

The master surface, upon which the front and back panels are bonded together, is shown in Figure 1. Figure 2 shows the pressure pad which is lowered onto the back panel and clamped during bonding, and Figure 3 is a photograph of the pressure pad, clamped in place, during the adhesive cure period.

3. OPTICAL TEST CONFIGURATION

Figure 4 is a photograph of the optical test configuration. Four components make up the configuration:

- Panel

- Panel fixture 
- Target

- Target positioning lines

The panel is mounted on the fixture and is held in place in a manner similar to that achieved when the panel is installed in the dish. The target is positioned in relation to the panel by three lines; all three lines are fastened at one end to the center of the target; the other end of one of these lines is tied to the center of the panel's inner edge, and the remaining two lines are each fastened to an outer corner of the panel. The lengths of the lines are such that the center of the target is positioned at the theoretical focal point of the panel when all three lines are taut.

Figure 5 shows the reflective panel mounted on the test fixture. The fixture is designed to simulate as closely as possible the panel edge boundary conditions which exist when all panels are installed in a complete dish. The fixture consists of:

- Two 1/8-in. thick steel members to which the panel is bolted at the panel flanges (Figure 6)

- Partial outer panel which, after rivetting or bolting to test panel, provides second mounting flange for test panel (also shown in Figure 6).

- Acurex Model 3011 parabolic trough torque tube mounted on a test cart

- Interface hirdware between steel beam members and torque tube (Figure 7)

Note that each pant: has only one mounting flange; the second flange is made available by the adjacent panel. Figure 8 shows a typical bolted (or riveted) joint between adjacent panels. 
The optical target is shown is Figure 9. The colors of the target are as follows:

\begin{tabular}{lc} 
Region/Band & $\begin{array}{c}\text { Outside Diameter } \\
\text { (in.) }\end{array}$ \\
\cline { 2 - 2 } Black (center) & 8 \\
Red & 12 \\
White & 16 \\
Green & 20 \\
Orange & 24
\end{tabular}

Also shown in the figure are the three positioning lines discussed above. 4. REVERSE IMAGE TEST RESULTS

Figure 10 is a photograph of the image of the target as reflected by the panel, viewed from a distance of $1400 \mathrm{ft}$. The image reflected by the panel was primarily black but also showed portions of the red and white rings and a very sriall amount of (less than 1 percent) green. This indicates that $99+$ percent of the reflected rays came from the region of a 16-in. aperture. The photograph was enlarged and the colored regions classified by percent of the total panel area. The classification yielded $79+$ percent black, 11 percent red, 9.5 percent white, and <1 percent green. A panel which fully meets our $2 \mathrm{mr}$ goal would be characterized by 95 percent black, 4.5 percent red, and 0.5 percent white. The target diameters were chosen somewhat arbitrarily to provide areas of distinction in the assessment of slope error. The image shows areas of high and lower compliance with the slope error goal for production panels, as discussed in the next section.

The lower compliance regions can be classified into several categories. They are:

- Edge effects

- Print-through of the back panel hat sections to the front panel 
- A minor front surface defect introduced during handing of the front panel

Each of the lower compliance regions can be improved in the prototype dish and in production by careful attention to the manufacturing techniques employed and by enjoying the benefit of proper mounting of the edges constraining each reflective panel into a more uniform curvature.

The edye effects will be largely improved by the mounting of adjacent panels. The primary region that will be affected is the narrow end of the panel.

Adjustment of the pressure applied during the bonding operation will reduce the print-through effect along both the top and bottom edges of the reflective panel. Experience with a second panel has shown that less pressure should be applied. Experience will be gained in the manufacture of additional panels prior to prototype dish fabrication.

The front sheet used on the first panel showed a small crease at approximately the center that was introduced during handling. Proper handing will eliminate this defect.

The prototype dish will incorporate the above improvements resulting in significantly improved slope error accuracy. 5.0 INTERPRETATION OF RESULTS

The three distinct intercept factors determined from the reverse image of the target can be plotted on a figure generated for the preliminary design review which relates intercept factor and various reflective panel slope errors. The figure is reproduced here as Figure 11 in an expanded receiver aperture range to include the black, red, and white regions of the target. These curves were generated by Georgia Tech Research Institute (GTRI) for an $\mathrm{f} / \mathrm{d}$ of 0.5 and zero pointing error. The three circled points at 4,6 , and 
$8 \mathrm{in}$. radii are the intercept factors from the reverse image test. These points generally fall in the 3.5 to $4 \mathrm{mr}$ panel slope error range.

Note from the figure that a $2 \mathrm{mr}$ reflective panel would have 95 percent of the panel area in the black region of the target. This is characteristic of the major, center portion of the panel as seen in the reverse image picture of Figure 10. The print-through pattern along the panel top and bottom edges can be reduced to the same level as the center portion with the use of less clamping force at the edges during the assembly process (more clamping force was applied at the edges than at the center during the bonding of the test panel). The lower focal quality of the narrow end of the panel is largely due to the unrestrained edge condition. When installed in a complete dish this edge will be ridgidly attached to the stiff outer edge of the inner panel, and thus have much better optical quality.

\section{DIRECT FOCUS TEST}

In an attempt to confirm the conclusions of focal quality drawn from the reverse image test, a direct focus was performed on the reverse image target with the sun as the light source. With the sun just above the horizon and the panel in a horizontal orientation (similar to the reverse image setup) a reasonable fous was achieved. The reverse image target was used very briefly to evaluate the visible concentrated spot size. The black and red areas of the target were uniformly illuminated with irregular portions of the white ring illuminated. This generally confirmed the results of the reverse image test.

To get an indication of the location of the high flux concentration in the illuminated area of the target, a piece of $1 / 10 \mathrm{in}$. thick fiberboard was utilized as a target. The fiberboard was left at the focal point until it burst into flame. The flame was extinguished and the fiberboard target 
photographed. This target is shown in Figure 12. The hole through the fiberboard is generally circular and approximately three in. in diameter. The burned spot is in the center of the highly illuminated area which, in turn, was approximately 10 to $12 \mathrm{in.} \mathrm{in} \mathrm{diameter.} \mathrm{The} \mathrm{teardrop} \mathrm{shaped} \mathrm{black} \mathrm{smudge}$ was caused by rising smoke, rather than an irregular spot shape. It may be concluded from figure 12 that the high flux density is contained in the area of the three-inch hole and $5 \mathrm{in}$. charred area.

\section{CONCLUSIONS}

The following conclusions were drawn from the test evaluation of the prototype reflective panel:

- The back panel stamping is of acceptable quality and meets the dimensional tolerances on parabolic shape $( \pm 0.060$ in., verified with the master surface)

- The feasibility of the panel design and assembly technique for the construction of high focal quality reflective elements has been demonstrated on the first attempt

- The one-sigma slope error of the first assembled panel was slightly better than $4 \mathrm{mr}$; not as good as the $2 \mathrm{mr}$ goal set in the concentrator design and optimization

- If a concentrator were constructed of panels similar in focal quality to the tested panel, an optimized receiver aperture would be 15 to $16 \mathrm{in}$. diameter giving a concentiation ratio of 1500 . The output of the concentrator (eneryy into the aperture) would be $161 \mathrm{~kW}_{\text {th }}$ at $1000 \mathrm{~W} / \mathrm{m}^{2}$ insolation.

- The major contributors to higher-than-goal slope errors identified through the reverse image test are: 
-- Print-through of the edge waffle pattern

-- Unconstrained narrow end

The former can largely be corrected through use of less clamping pressure during the bonding step of assembly. The latter will be corrected in the full dish assembly, in that the inner panel provides the requireci outer panel narrow end contour

- By incorporating the improvements mentioned above, the existing design can provide a prototype concentrator that exhibits $2 \mathrm{mr}$ panels

Phase I work will be completed with the assembly and test of an additional two prototype outer panels. Two panels of the 4 produced in Phase I will be delivered to Sandia in mid-March for further evaluation during Phase II. 


\section{REFERENCES}

1. Overly, P., et al, "Innovative Point Focus Solar Concentrator, Preliminary Design, Task 1, 2(a), Topical Keport," Acurex Technical Report, TK-85-178-EED, November 1985. 


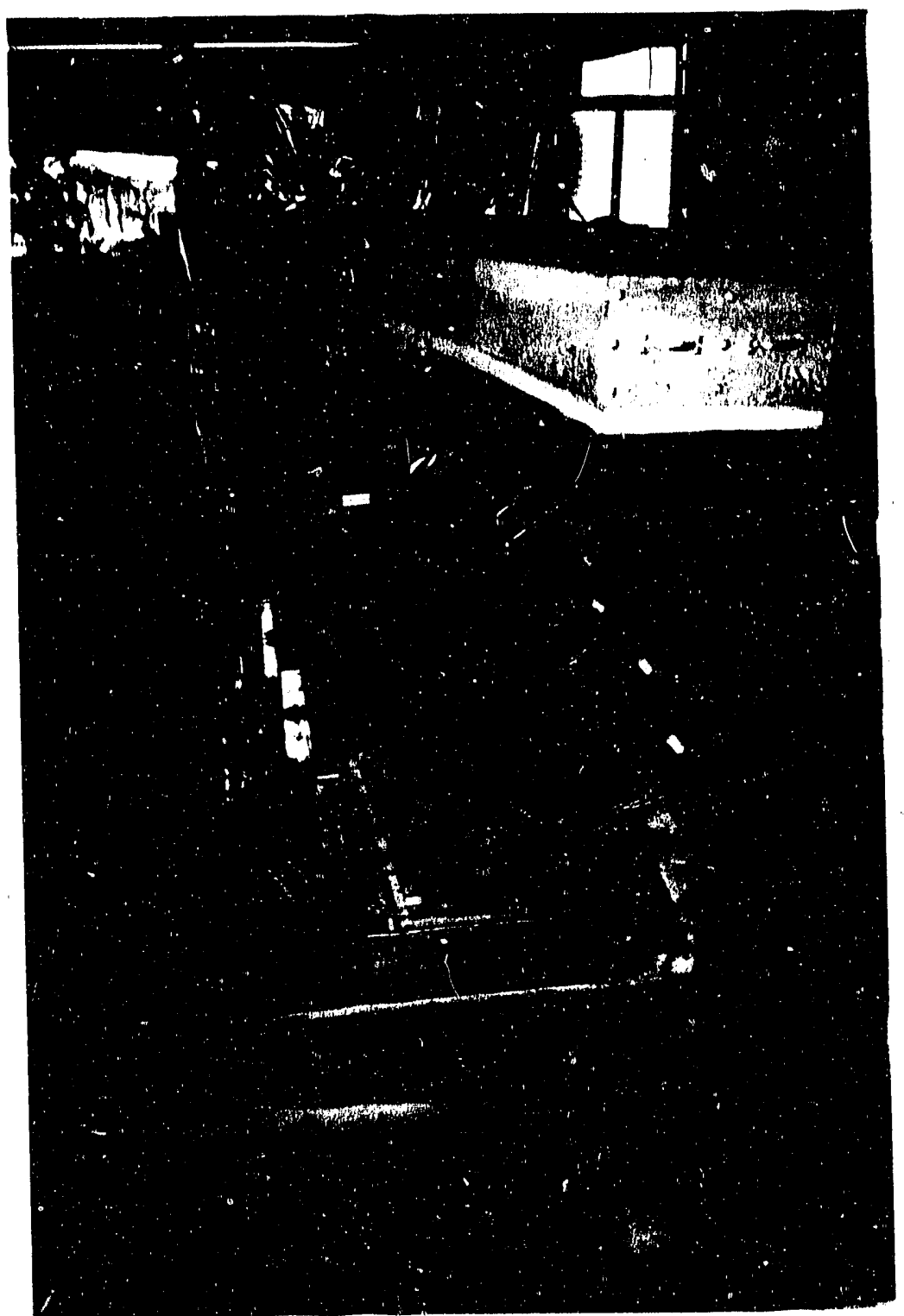

Figure 1. Master Surface 


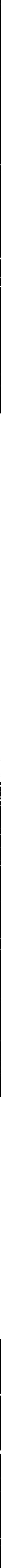




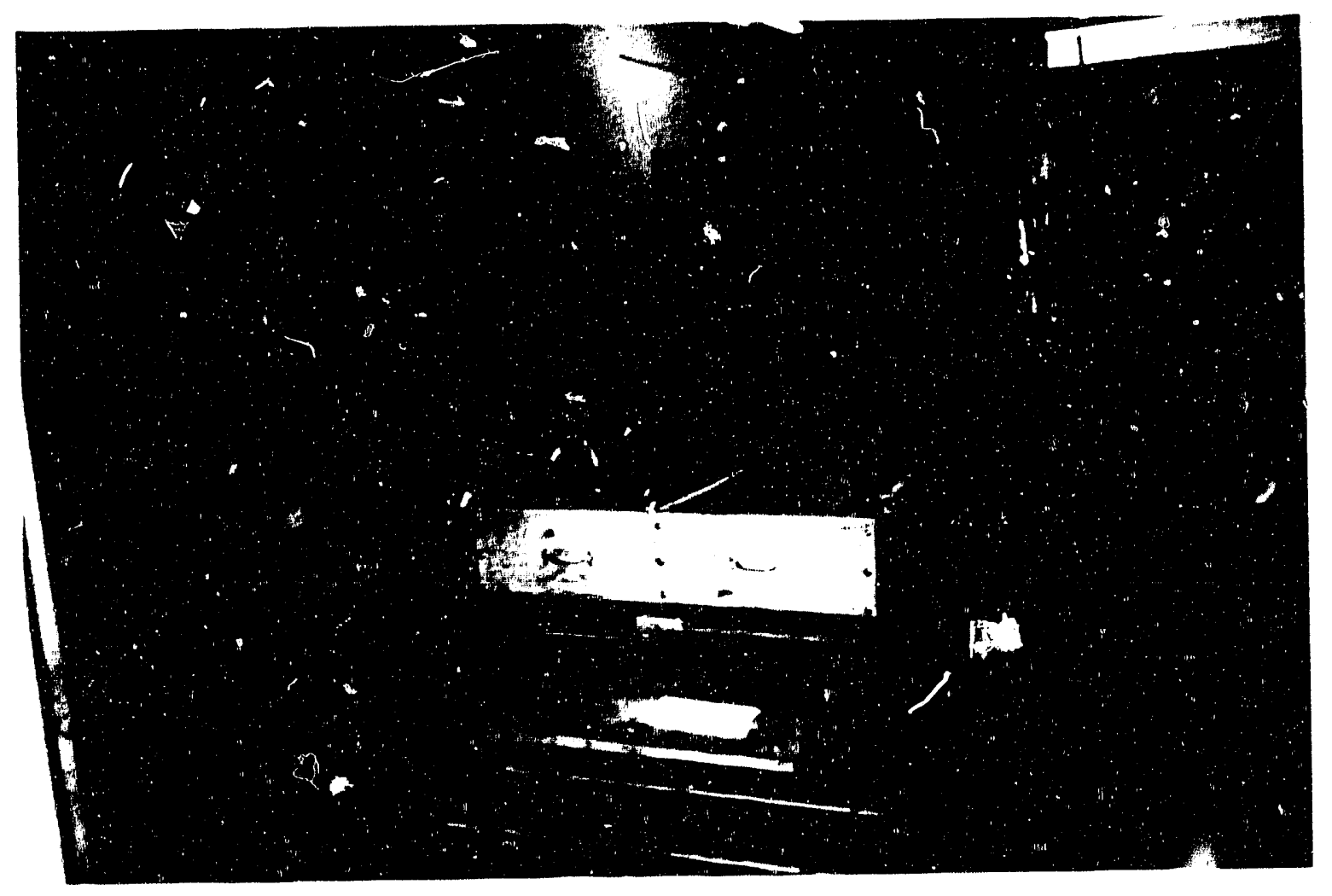

Figure 3. Pressure Pad Clamped in Place during Cure 


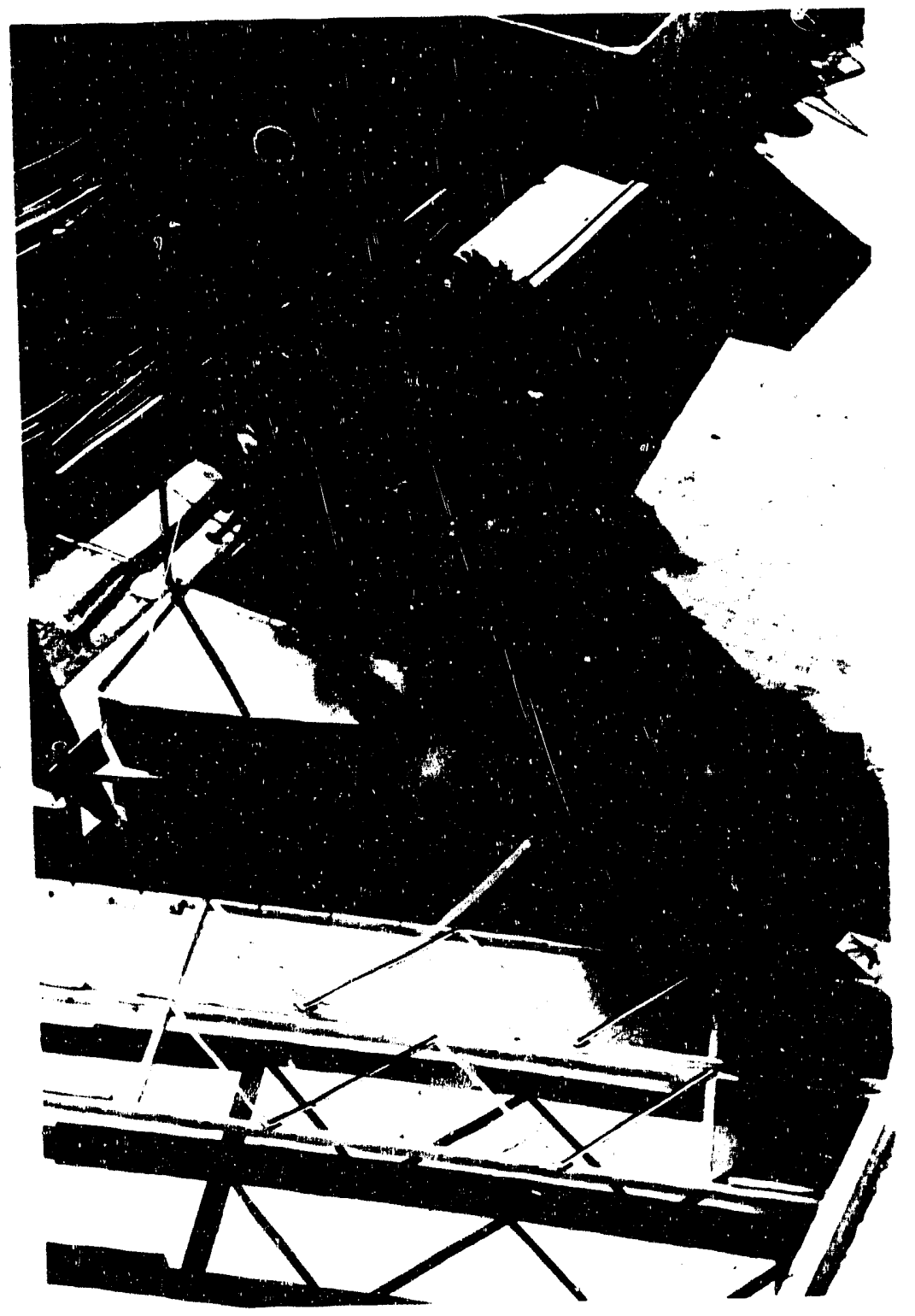

Figure 4. Uptical Test Configuration 


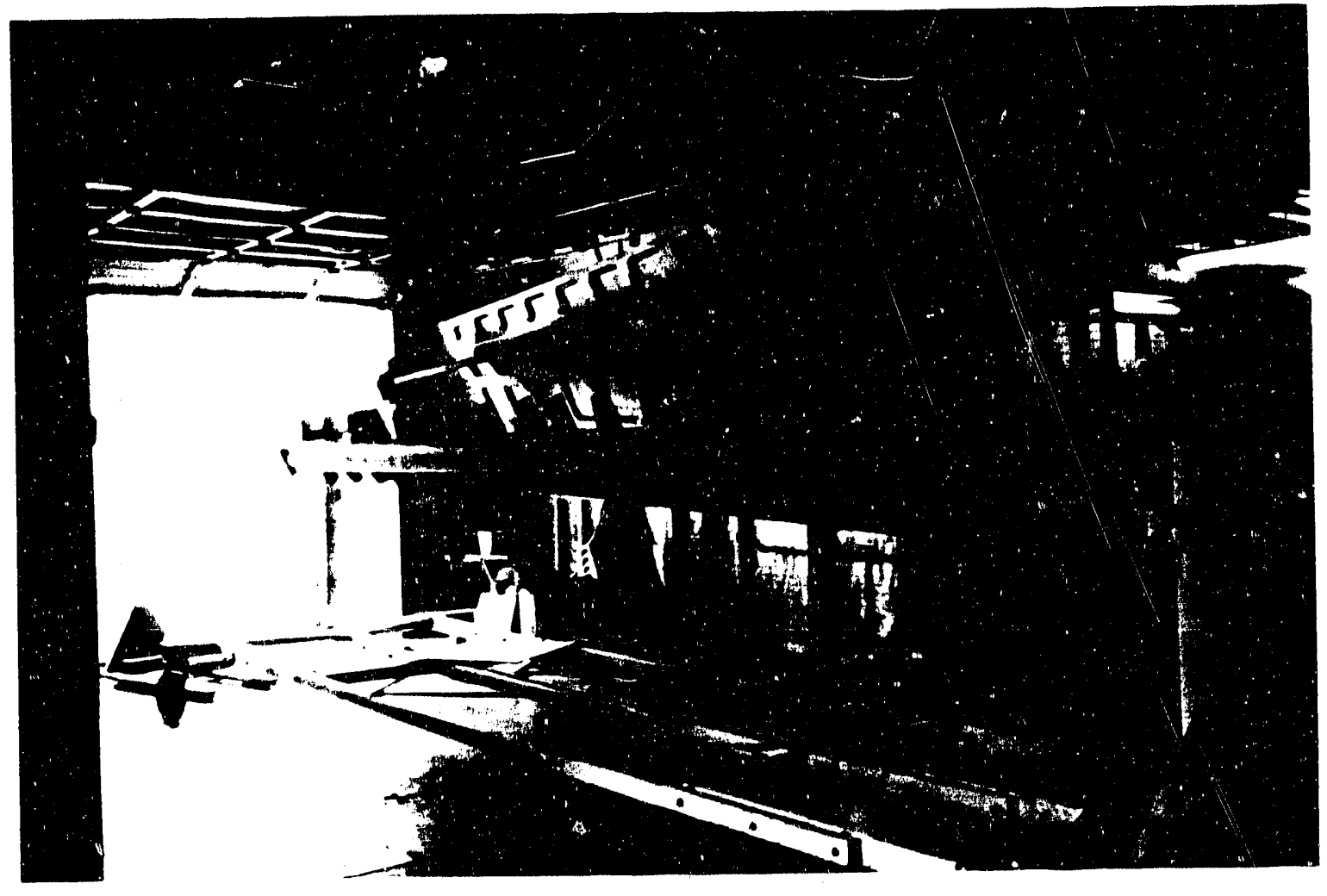

Figure 5. Panel Mounted on Test Fixture 


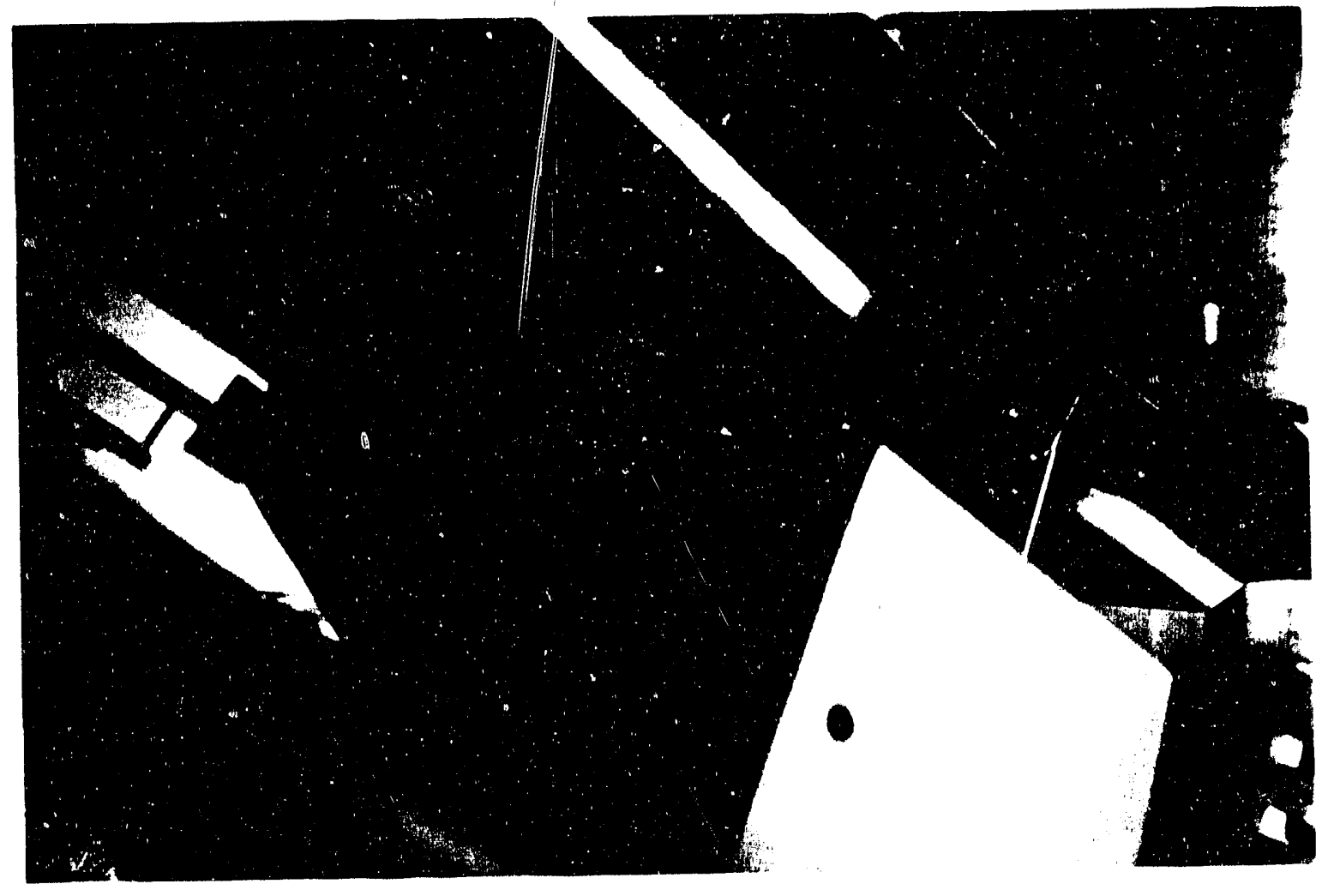

Figure 6. Panel/Fixture Mounting Interface 


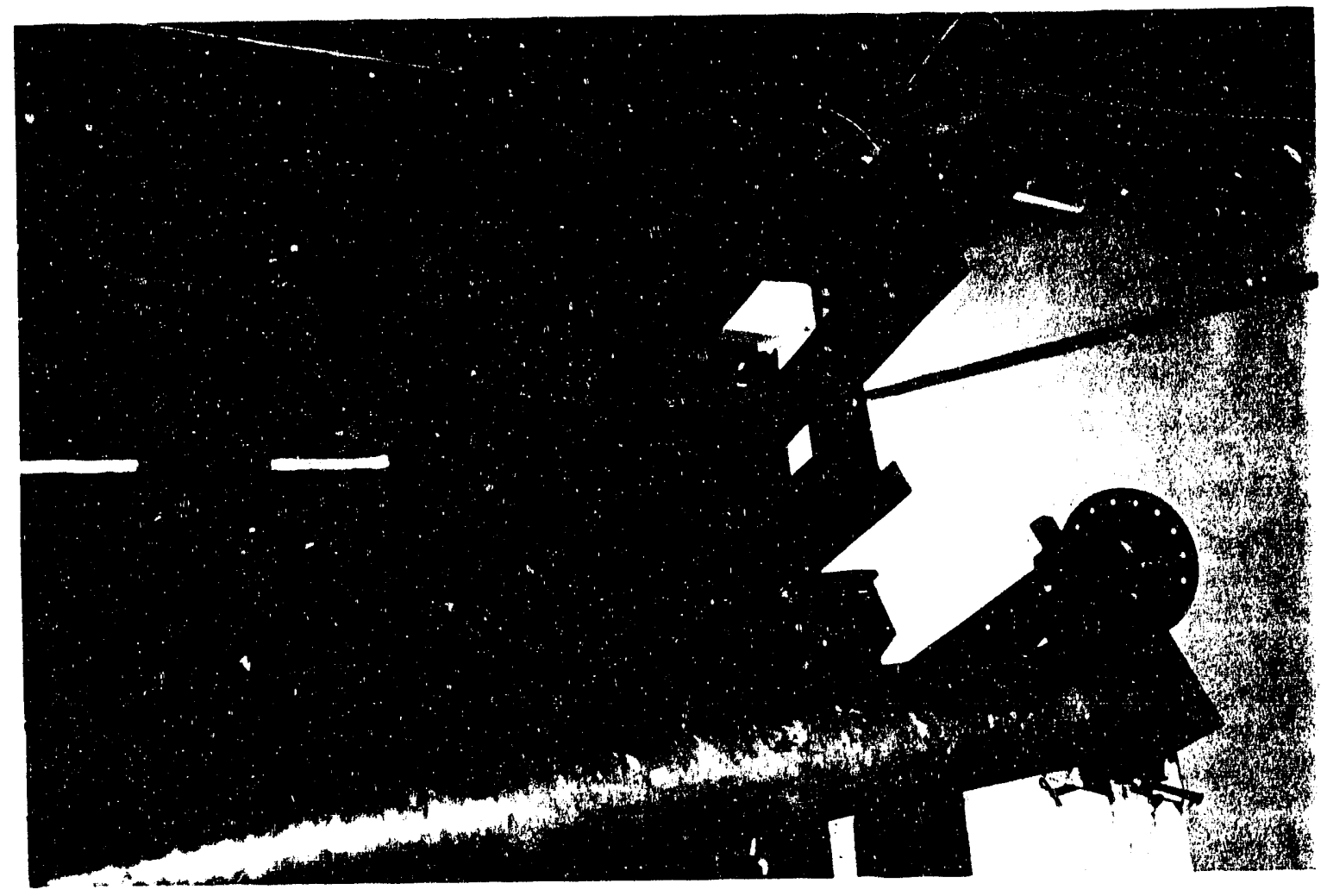

Figure 7. Panel/Fixture Interface Hardware 


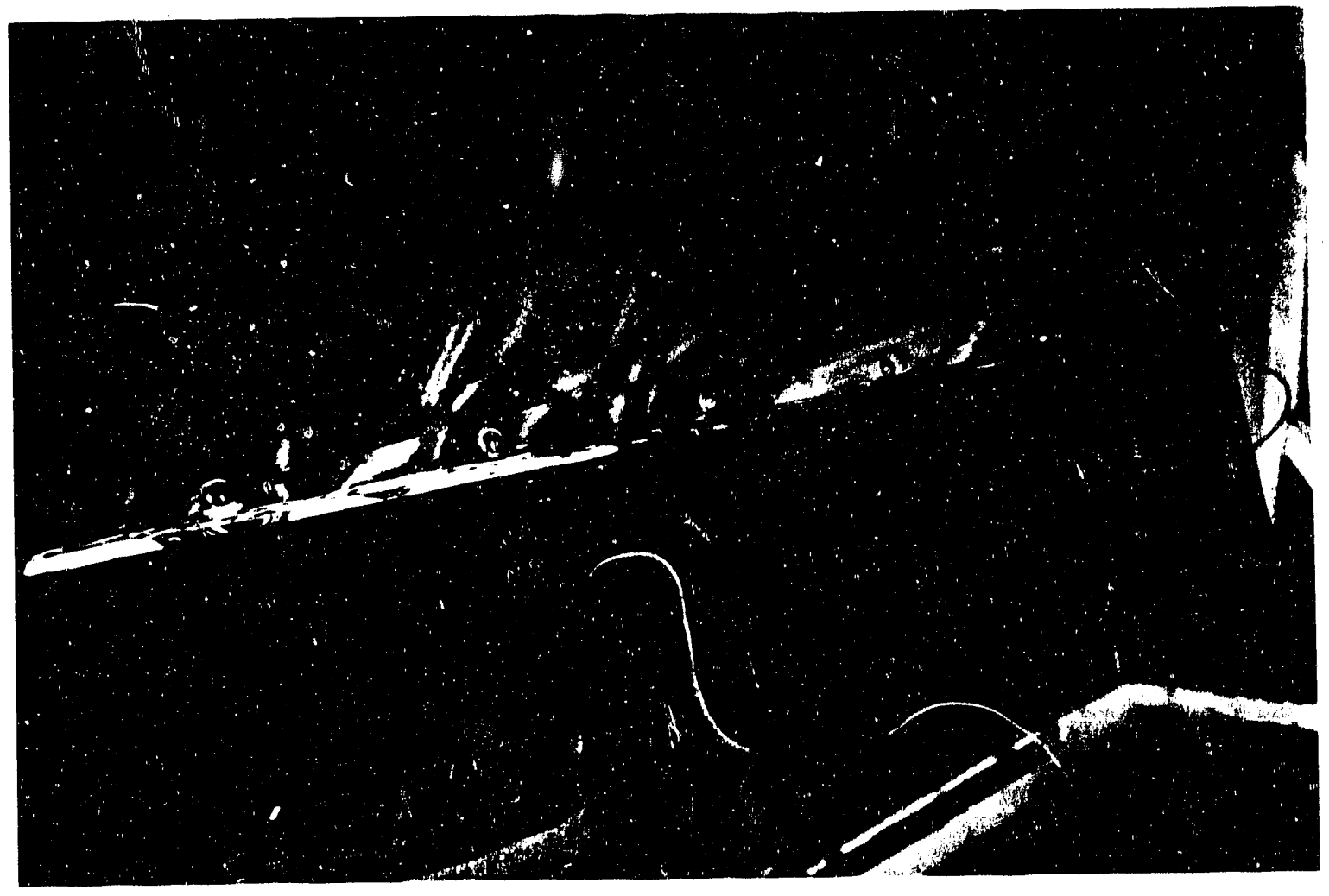

Figure 8. Interpanel Joint 


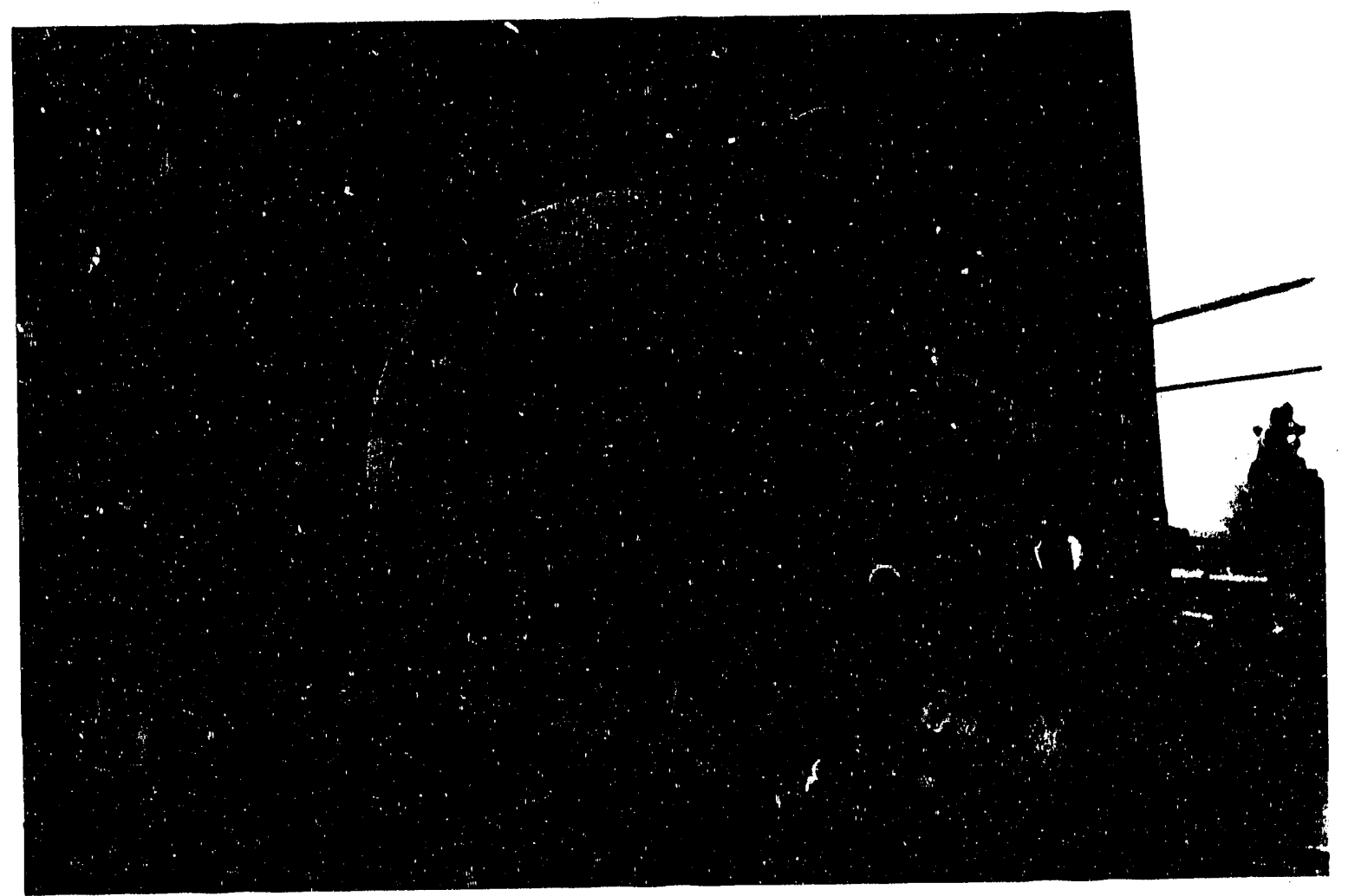

Figure 9. Optical Target 


$$
\text { x o }
$$

4 


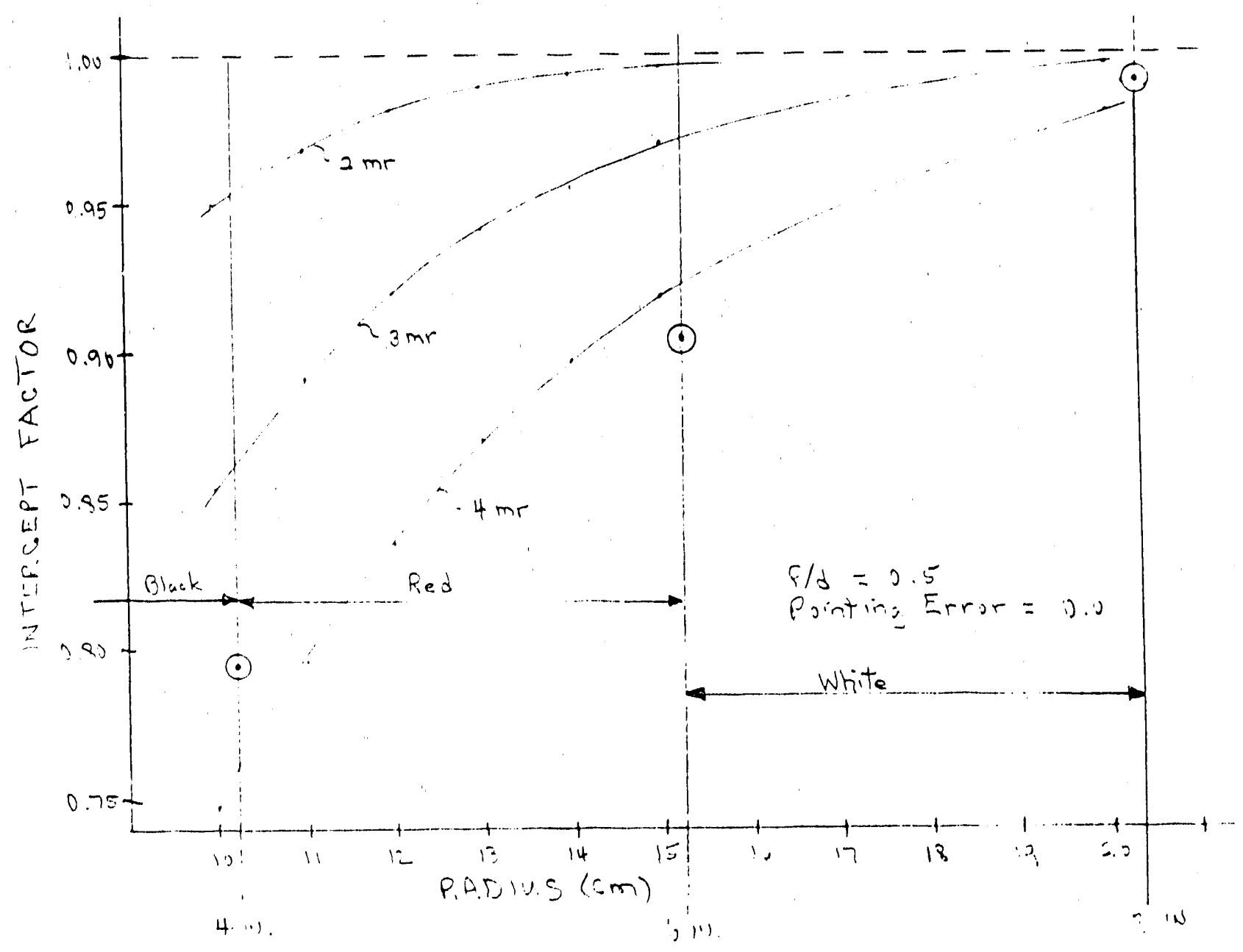

Figure 11. Panel Slope Error 


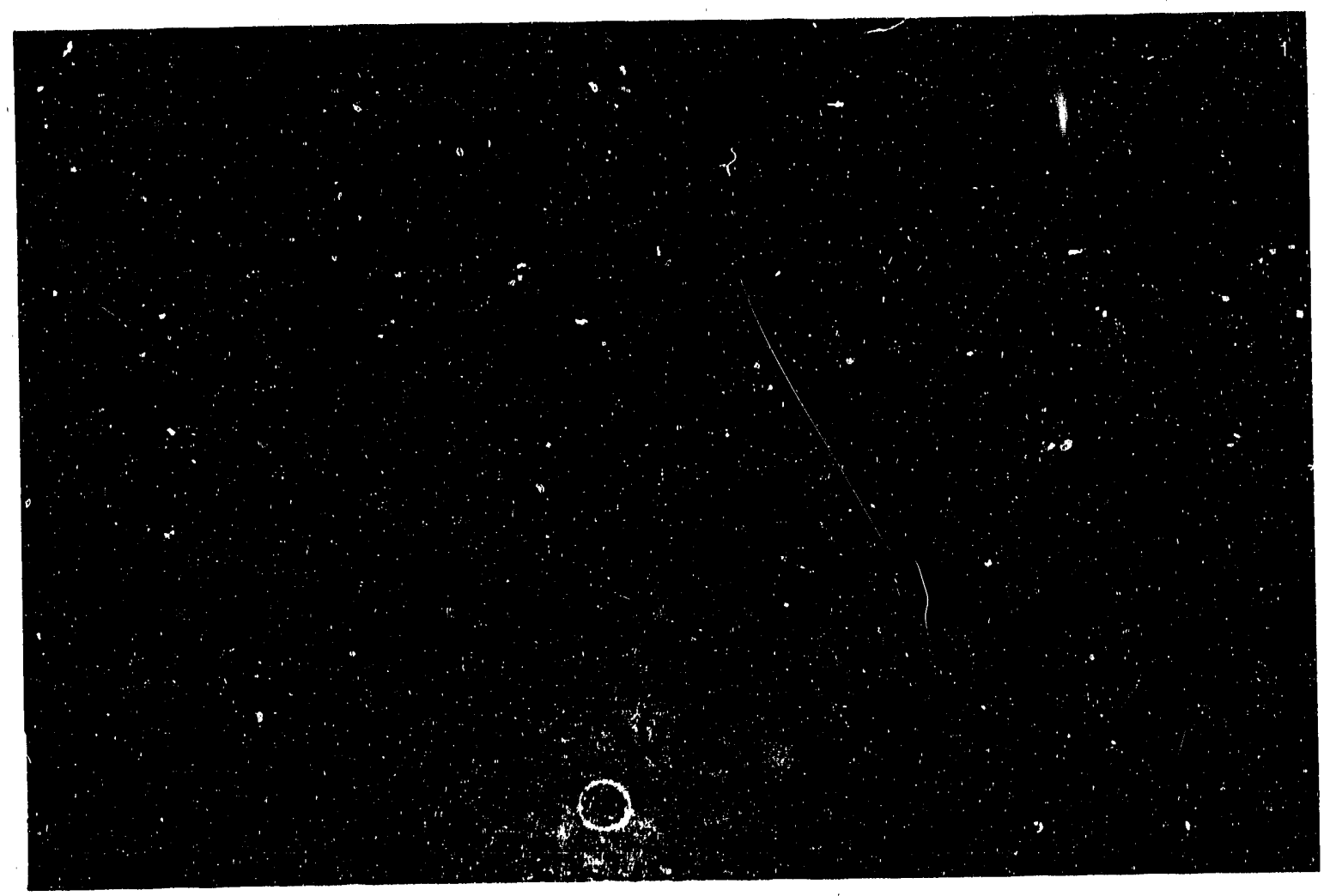

Figure 12. Direct Focus Test 

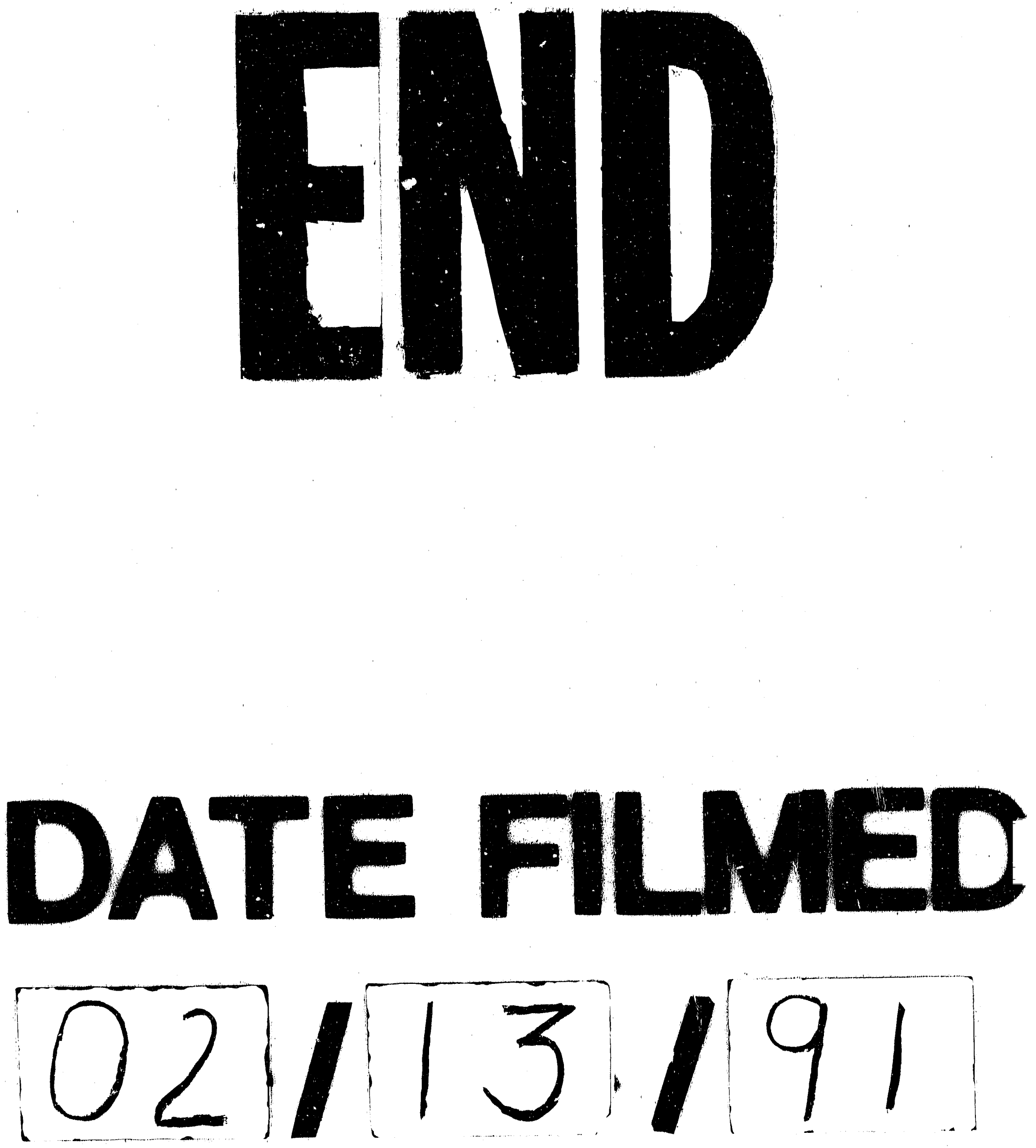

$=$ 